\title{
Food Allergen-induced IgE Response Mouse Model Created by Injection of in vitro Differentiated Th2 Cell Culture and Oral Antigen Intake
}

\author{
Kyoko SHIBAHARA ${ }^{1,2}$, Haruyo NAKAJIMA-ADACHI ${ }^{1}$, Osamu KAMINUMA ${ }^{3}$, Takachika HIROI $^{3}$, Akio MORI $^{4}$ \\ and Satoshi HACHIMURA ${ }^{1,2 *}$ \\ ${ }^{1}$ Research Center for Food Safety, Graduate School of Agricultural and Life Sciences, The University of Tokyo, 1-1-1 Yayoi, \\ Bunkyo-ku, Tokyo 113-8657, Japan \\ ${ }^{2}$ Department of Applied Biological Chemistry, Graduate School of Agricultural and Life Sciences, The University of Tokyo, 1-1-1 Yayoi, \\ Bunkyo-ku, Tokyo 113-8657, Japan \\ ${ }^{3}$ Department of Genome Medicine, Pollen Allergy Project, Tokyo Metropolitan Institute of Medical Science, 2-1-6, Kamikitazawa, \\ Setagaya-ku, Tokyo 156-8506, Japan \\ ${ }^{4}$ Clinical Research Center for Allergy and Rheumatology, National Hospital Organization, Sagamihara National Hospital, 18-1 \\ Sakuradai, Sagamihara-shi, Kanagawa 252-0392, Japan
}

Received May 8, 2013; Accepted August 16, 2013

Immunoglobulin (Ig) $\mathrm{E}$ is a mediator of food allergic reaction; however, the mechanisms of its production in response to an ingested antigen are not fully understood. For analysis of IgE production, here we propose an IgE response mouse model created by injection of a Th2 cell culture and feeding of an egg white diet. According to this manipulation, total and ovalbumin specific IgE production were elevated in this model. We think our model enables us to analyze IgE induction by Th2 cells in food allergy and can contribute to the development of a treatment for food allergy.

Key words: Th2 cell, IgE, food allergy

Food allergy is raised by adverse immune reaction to a food protein with various symptoms including lifethreatening anaphylaxis. Several papers have reported that the number of patients allergic to food proteins has been increasing recently, particularly in children in developed countries $[1,2]$. In food allergic patients, Th2 immune responses are significantly activated in response to food antigens, whereby Th2 cells play an important role in establishment of food allergic inflammation. The Th2 cell is the phenotype of $\mathrm{CD}^{+}$helper $\mathrm{T}$ cells that produces Th2 cytokines including IL-4, IL-5 and IL-13. These cytokines mediate allergic responses in many ways, for example, by instructing B cells to produce immunoglobulin (Ig) E, activating mast cells or basophils, and attracting eosinophils at the site of allergic inflammation [3]. Among them, IgE is the important mediator of food allergic reaction because it cross-links the Fce receptor on mast cells or basophils and makes

\footnotetext{
*Corresponding author. Mailing address: Satoshi Hachimura, Research Center for Food Safety and Department of Applied Biological Chemistry, Graduate School of Agricultural and Life sciences, The University of Tokyo, 1-1-1 Yayoi, Bunkyo-ku, Tokyo 113-8657, Japan. Phone: +81 3-5841-5230, Fax: +81 3-5841-5230. E-mail: ahachi@mail.ecc.u-tokyo.ac.jp
}

them to degranulate to elicit acute anaphylaxis [4]. Class switching in antigen-specific B cells is enhanced to $\operatorname{IgE}$ from IgM by interaction with Th2 cells. To reduce $\operatorname{IgE}$ responses for treatment of food allergy, we need to clarify the mechanisms of excess production of serum $\operatorname{IgE}$ in patients, but this has not been fully understood.

To clarify the mechanisms, mouse models are very helpful, and many features of food allergy have been clarified by using them [5-8]. However, it is difficult to examine how antigen-specific IgE production is elevated under inflammatory Th2 circumstances in food allergy model mice sensitized by an antigen coadministered with adjuvant and induced by subsequent antigen feeding. In these models, the source of antigen-specific T cells is not definitely identified, and the process of differentiation to the Th2 phenotype cannot be followed up.

To overcome these problems, we exploited a new food allergen-induced IgE response mouse model that was created by only antigen-specific Th2 cell culture transfer and oral antigen ingestion using Rag2gene-deficient and $\mathrm{T}$ cell receptor (TCR) transgenic mice. To the best of our knowledge, this is the first report to show that by adoptive transfer of in vitro differentiated antigen-specific Th2 cell culture to wild type mice, the serum IgE level was elevated in response to an ingested antigen. 
A

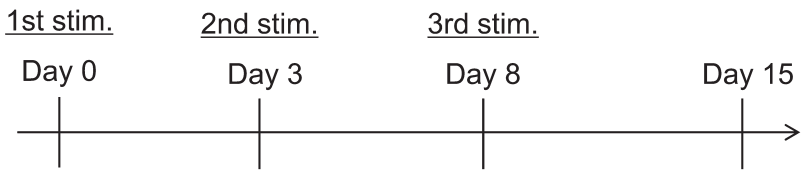

B

IL-4

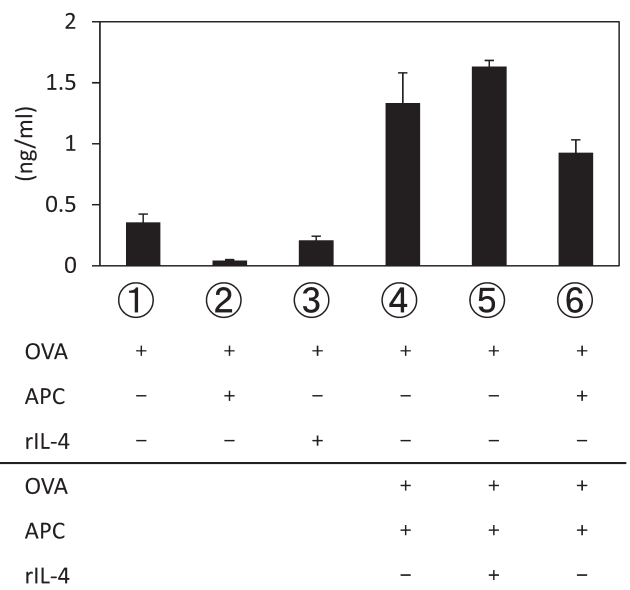

IFN- $\gamma$

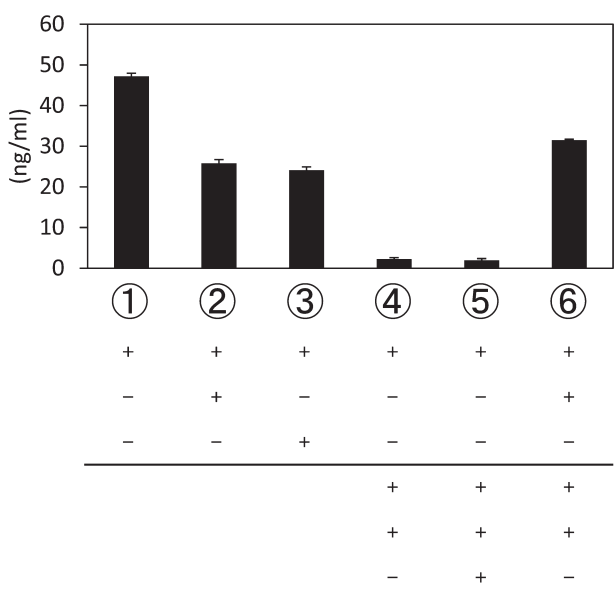

Fig. 1. Th2 cells differentiated under several culture conditions.

(A) The schedule of stimulation to create polarized Th2 cells. (B) Naïve CD4 ${ }^{+} \mathrm{T}$ cells from splenocytes of Rag2 $2^{-/-} \mathrm{DO} 11.10$ mice were cultured under several Th2-skewing conditions, which are shown under the Figure. T cells $\left(1 \times 10^{5}\right.$ cells/well $)$ differentiated under each condition were restimulated with APCs $\left(4 \times 10^{5}\right.$ cells/well $)$ and OVA $(1.0 \mathrm{mg} / \mathrm{ml})$ for 48 hours, and cytokine productions were measured by ELISA.

To prepare antigen-specific $\mathrm{CD}^{+} \mathrm{T}$ cells, we used Rag $2^{-/}$DO11.10 mice with the Balb/c background, which are Rag2gene-deficient and ovalbumin (OVA) specific TCR transgenic mice. All T cells in this mouse express an OVA-specific TCR. These mice were originally provided by Dr. Y. Wakatsuki (Graduate School of Medicine, Kyoto University), and breeding was consigned to Sankyo Labo Service Corporation Inc (Tokyo, Japan). Balb/c mice were purchased from CLEA Japan Inc. (Tokyo, Japan). These mice were housed under specific pathogen free conditions at the University of Tokyo. Female mice, over 8 weeks old, were used for this research. All experiments were performed in accordance with guidelines for animal care and use of the University of Tokyo.

Antigen-specific Th2 cells were induced from splenic $\mathrm{CD}^{+} \mathrm{T}$ cells of Rag2 ${ }^{-/-}$DO11.10 mice in vitro. Initially, we prepared single-cell suspensions from splenocytes of Rag2 ${ }^{-/-}$DO11.10 mice. $\mathrm{CD}^{+} \mathrm{T}$ cells were isolated by using a MACS cell separation system (Miltenyi Biotec, Bergisch Gladbach, Germany). For antigen stimulation of $\mathrm{CD}^{+} \mathrm{T}$ cells in the culture, single-cell suspensions of splenocytes obtained from Balb/c mice treated with mitomycin C (Sigma-Aldrich, St. Louis, MO, USA) were used as antigen-presenting cells (APCs).

To differentiate naïve $\mathrm{CD}^{+} \mathrm{T}$ cells to polarized $\mathrm{Th} 2$ cells, we tried the 6 protocols of culture summarized in Fig. 1A and the lower part of Fig. 1B. In all protocols, $\mathrm{CD}^{+}$splenic $\mathrm{T}$ cells from $\mathrm{Rag}^{-/-} \mathrm{DO} 11.10$ mice $\left(1 \times 10^{5}\right.$ cells/well $)$ were initially stimulated with $10 \mathrm{mg} /$ $\mathrm{ml}$ OVA (Sigma-Aldrich), $5 \mathrm{ng} / \mathrm{ml}$ recombinant (r) IL-4 (PeproTech, Rocky Hill, NJ, USA) and $5 \mu \mathrm{g} / \mathrm{ml}$ anti-IL-12 (clone C17.20.8) with APCs $\left(4 \times 10^{5}\right.$ cell/ well) in 96-well round-bottom plates in $100 \mu \mathrm{l}$ complete RPMI medium (Nissui, Tokyo, Japan). On day 3, cells were collected and washed, and $1 \times 10^{6}$ cells/well were stimulated with $10 \mathrm{mg} / \mathrm{ml}$ OVA again in a 24-well plate(s) in $1.5 \mathrm{ml}$ medium. To seek an appropriate Th2 cell-inducing protocol, we stimulated the cells by 2 different ways in addition to OVA for further culture; (1) in protocols 2 and 6 , APCs $\left(4 \times 10^{6}\right.$ cells/well) were added, and (2) in protocol 3, rIL-4 $(5 \mathrm{ng} / \mathrm{ml})$ was added. On day 8 , cells were collected, and cells in protocols $1-3\left(1 \times 10^{5}\right.$ cells/well) were restimulated with APCs $\left(4 \times 10^{5}\right.$ cells/ well) and OVA $(1 \mathrm{mg} / \mathrm{ml})$ to examine IL-4 and IFN- $\gamma$ production. After 48 hours of incubation, supernatants were collected and stored at $-20^{\circ} \mathrm{C}$ for further analysis. 
On the other hand, cells of protocols 4-6 were washed again, and $1 \times 10^{6}$ cells/well were stimulated a third time with OVA $(10 \mathrm{mg} / \mathrm{ml})$ and APCs $\left(4 \times 10^{6}\right.$ cells/well $)$ in $24-$ well plates on day 8 . In protocol 5 , rIL-4 $(5 \mathrm{ng} / \mathrm{ml})$ was added. On day 15 , cells in protocols 4-6 were collected and restimulated as in protocols 1-3 on day 8 to examine IL-4 and IFN- $\gamma$ production.

IL-4 and IFN- $\gamma$ levels in the supernatants were detected by sandwich ELISA. The wells of an immunoplate (Nunc, Roskilde, Denmark) were coated with rat anti-mouse IL-4 (BD Pharmingen, San Jose, CA, USA; clone 11B11) or rat anti-mouse IFN- $\gamma$ (BD Pharmingen; clone R4-6A2) mAbs respectively. After blocking with BSA, the test samples and standard cytokine preparations were added. Subsequently, bound cytokines were detected by biotinylated rat anti-mouse IL-4 (BD Pharmingen; clone BVD6-24G2) or rat anti-mouse IFN- $\gamma$ (BD Pharmingen; clone XMG1.2) mAbs, respectively, followed by streptavidin-alkaline phosphatase conjugate (BD Pharmingen), and enzyme substrate ( $p$-nitrophenylphosphatase).

We tested these protocols to determine which was most effective for induction of Th2 cells and found that protocols 4 and 5 showed higher IL-4 production and lower IFN- $\gamma$ production than other protocols (Fig. 1B). Since the two protocols differed only in that in one rIL4 was added in the third antigenic stimulation and the results were similar, we decided to use protocol 4 without adding rIL-4 in the third stimulation. It was unexpected that protocols 4 and 6 would differ so much in IFN- $\gamma$ production, since the difference between these two protocols was only whether APCs were added at the 2nd stimulation. APCs added at the 2nd stimulation seemed to induce a Th1-shifted response. Confirming protocol 4 in brief, naïve Splenic $\mathrm{CD}^{+} \mathrm{T}$ cells were initially stimulated on day 0 as described above. Cells were collected on day 3 , and $1 \times 10^{6}$ cells/well were restimulated with OVA $(10 \mathrm{mg} / \mathrm{ml})$ in 24 -well plates in $1.5 \mathrm{ml}$ medium. On day 8 , cells were collected again and restimulated with OVA $(10 \mathrm{mg} / \mathrm{ml})$ and APCs $\left(4 \times 10^{6}\right.$ cells $/$ well $)$ in 24 -well plates in $1.5 \mathrm{ml}$ medium. On day 15 , cells were collected for adoptive transfer to naïve wild-type mice. Media were added appropriately during this culture period. $\mathrm{T}$ cells differentiated by this protocol were efficiently polarized to Th2, secreting more IL-4 and less IFN- $\gamma$ than naïve $\mathrm{CD}^{+}$T cells from Rag2 ${ }^{--}$DO11.10 mice (Fig. 2A).

To elicit a response to orally administrated allergen protein in wild-type mice, Th2 cell cultures made in protocol 4 were adoptively transferred into naive Balb/c mice by intravenous injection $\left(2 \times 10^{7}\right.$ cells/head). On the day after transfer, these Balb/c mice started to be fed an egg white diet (EW diet; Funabashi Farm, Funabashi, Japan) or control diet (CE-2 diet; CLEA Japan Inc.) which was fed to them 14 days. After EW or CE-2 diet feeding, blood was collected, and the serum was separated. The schedule for this is summarized in Fig. 2B.

We assessed the quantities of total IgE and OVAspecific IgE, IgG1 and IgG2a in the sera. Determination of total and OVA-specific IgE levels was carried by ELISA. To determine the total and OVA-specific IgE levels, wells were coated with rat anti-mouse IgE $\mathrm{mAb}$ (BD Pharmingen; clone R35-92) or OVA, respectively, with biotinylated rat anti-mouse IgE $\mathrm{mAb}$ (Serotec, clone LO-ME-2) as the detection antibody. Then, streptavidinalkaline phosphatase conjugate and an enzyme substrate ( $p$-nitrophenylphosphatase) were subsequently added. Mouse IgE mAb (BD Pharmingen), or pooled serum obtained from Balb/c mice immunized with OVA and alum were used as standards. To assay OVA-specific IgG1 and IgG2a, the wells were coated with OVA. After the test samples were added, bound antibodies were detected by means of alkaline phosphatase-conjugated anti-mouse IgG1 and IgG2a antibodies (Zymed, Carlsbad, CA, USA). The OVA-specific antibody levels were expressed as relative units.

As a result, total IgE was significantly elevated in Th2 cell culture-injected/EW-fed (Th2/EW) mice compared with PBS-injected/EW-fed (PBS/EW) mice or Th2 cell culture-injected/CE-2-fed (Th2/CE-2) mice (Fig. 3A). The OVA-specific IgE level increased in Th2/CE-2 mice compared with $\mathrm{PBS} / \mathrm{EW}$ mice, although this was not statistically significant (Fig. 3B). This phenomenon can be explained by the small number of APC, contained in the injected Th2 cell culture, which possessed OVA induced IgE production. It was already reported that injection of naïve mice with dendritic cells (DCs) from allergic mice induced antigen-specific IgE production [9]. Similar to this report, DCs may play some role in our model. More remarkably, Th2/EW mice showed significantly higher OVA-specific IgE production compared with PBS/EW mice. Taken together, these results suggest that injected Th2 cells responded to OVA in the EW diet and facilitated IgE production.

To confirm that a Th2 response was facilitated in Th2/EW mice, OVA-specific IgG1 and IgG2a were also measured. OVA-specific IgG1 was significantly higher in Th2/EW mice than in PBS/EW mice or Th2/CE-2 mice (Fig. 3B). On the other hand, there was no significant difference in OVA-specific IgG2a production, although the antibody titers in Th2/EW mice tended to be higher than in the other groups. This result confirmed that Th2 culture injection and antigen ingestion induced Th2- 
A

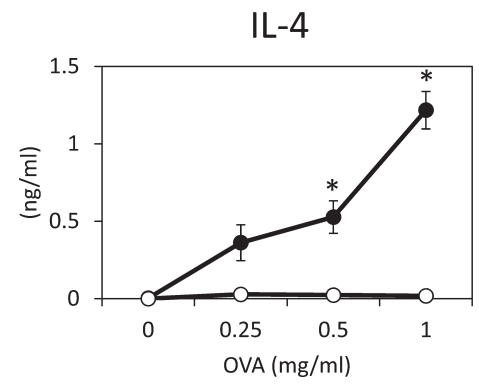

IFN- $\gamma$

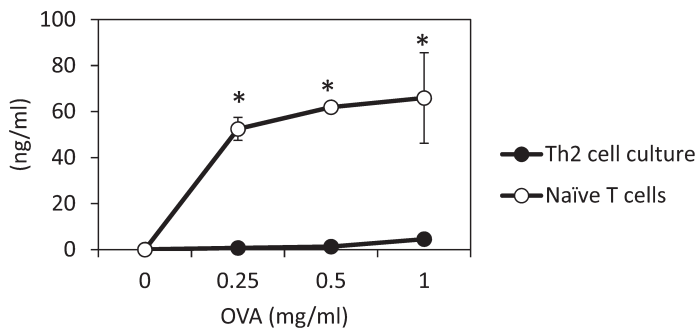

B

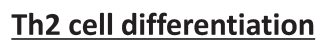

Transfer and feeding

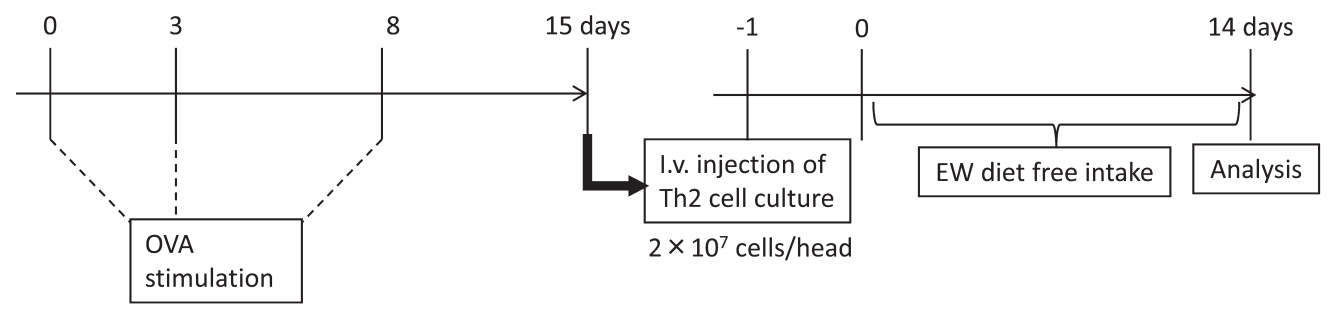

Fig. 2. Antigen-specific cytokine responses of differentiated Th2 cells and the protocol used to elicit IgE responses in Balb/c mice.

(A) Naïve $\mathrm{CD}^{+} \mathrm{T}$ cells and Th2 cells differentiated under the most appropriate condition $\left(1 \times 10^{5}\right.$ cells/well $)$ were respectively stimulated with APCs $\left(4 \times 10^{5}\right.$ cells/well $)$ and OVA $(0,0.25,0.5$ and $1.0 \mathrm{mg} / \mathrm{ml})$ for 48 hours, and cytokine productions were measured by ELISA. Values are means \pm SE. Statistic analysis was performed by Student's t-test analysis (*p<0.05 compared with naïve T cells). (B) Naïve CD4 ${ }^{+} \mathrm{T}$ cells from splenocytes of Rag2 $2^{-/} \mathrm{DO} 11.10$ mice $\left(1 \times 10^{5}\right.$ cells $/$ well $)$ were stimulated with OVA $(10 \mathrm{mg} / \mathrm{ml})$, rIL-4 $(5 \mathrm{ng} / \mathrm{ml})$ and anti-IL-12 $(5 \mu \mathrm{g} / \mathrm{ml})$ in the presence of APCs $\left(4 \times 10^{5}\right.$ cells $/$ well $)$. On day 3 , cells were collected and restimulated $\left(1 \times 10^{6}\right.$ cells $/$ well $)$ with OVA $(10 \mathrm{mg} / \mathrm{ml})$. On day 8 , cells were collected again and restimulated $\left(1 \times 10^{6}\right.$ cells $/$ well $)$ with OVA $(10 \mathrm{mg} / \mathrm{ml})$ in the presence of APCs $\left(4 \times 10^{6}\right.$ cells/well). On day 15 , Th2 cell cultures were collected and suspended in PBS. These cells $\left(2 \times 10^{7}\right.$ cells/head $)$ were intravenously injected into naïve Balb/c mice, and the mice were fed the EW diet from the day after injection for 14 days. After feeding of the EW diet, blood was collected, and Ig in the sera was analyzed by ELISA.

dominant responses. Collectively, we have shown here in this mouse model that IgE production was elevated by Th2 cell culture injection and an EW diet.

Many food allergy mouse models have been created, and mechanisms of allergic reaction have been clarified by using them [5-8]. Most models use an adjuvant to elevate OVA-specific IgE production, the detailed mechanism of which is unknown. Some groups showed that $\mathrm{CD} 4^{+} \mathrm{T}$ cells prepared from mice with food allergic inflammation transfer intestinal immune and allergic responses to naïve wild-type mice $[10,11]$. While there is no doubt that the Th2 cell is important for food allergic responses, there has been no model that could clarify how Th2 cells that elevate IgE production are induced. The important feature of our mouse model shown here is that total and OVA-specific IgE are elevated in the wild-type mouse by in vitro differentiated Th2 culture and antigen ingestion. This model may be applied to analyze what kind of Th2 cell, i.e., Th2 cells differentiated under what kinds of conditions, induce B cell class switch to IgE. So, our model is thought to be helpful to analyze $\operatorname{IgE}$ production evoked by $\mathrm{Th} 2$ cells in response to an orally administrated antigen in vivo.

Our group previously reported that OVA23-3 mice transgenic for OVA 323-339-specific TCR develop a food allergic reaction in response to consumption of EW diet only [12]. In this model, antigen-specific Th2 cells are suggested to be important for inducing food allergic reaction. So we also tried to induce Th2 cells from Rag2 $2^{--}$OVA23-3 mice in vitro in addition to Th2 cells from Rag2 ${ }^{-1}$ DO11.10 mice. While $\mathrm{CD} 4^{+} \mathrm{T}$ cells from naïve Rag2 ${ }^{-/}$OVA23-3 mice had been confirmed to produce more IL-4 than those from Rag2 $2^{--}$DO11.10 mice [13], we could not efficiently induce Th2 cells from Rag2 ${ }^{-/}$OVA23-3 mice in vitro (Shibahara K, Kikuchi A, Toda $\mathrm{M}$ and Nakajima-Adachi $\mathrm{H}$; unpublished data). 
A
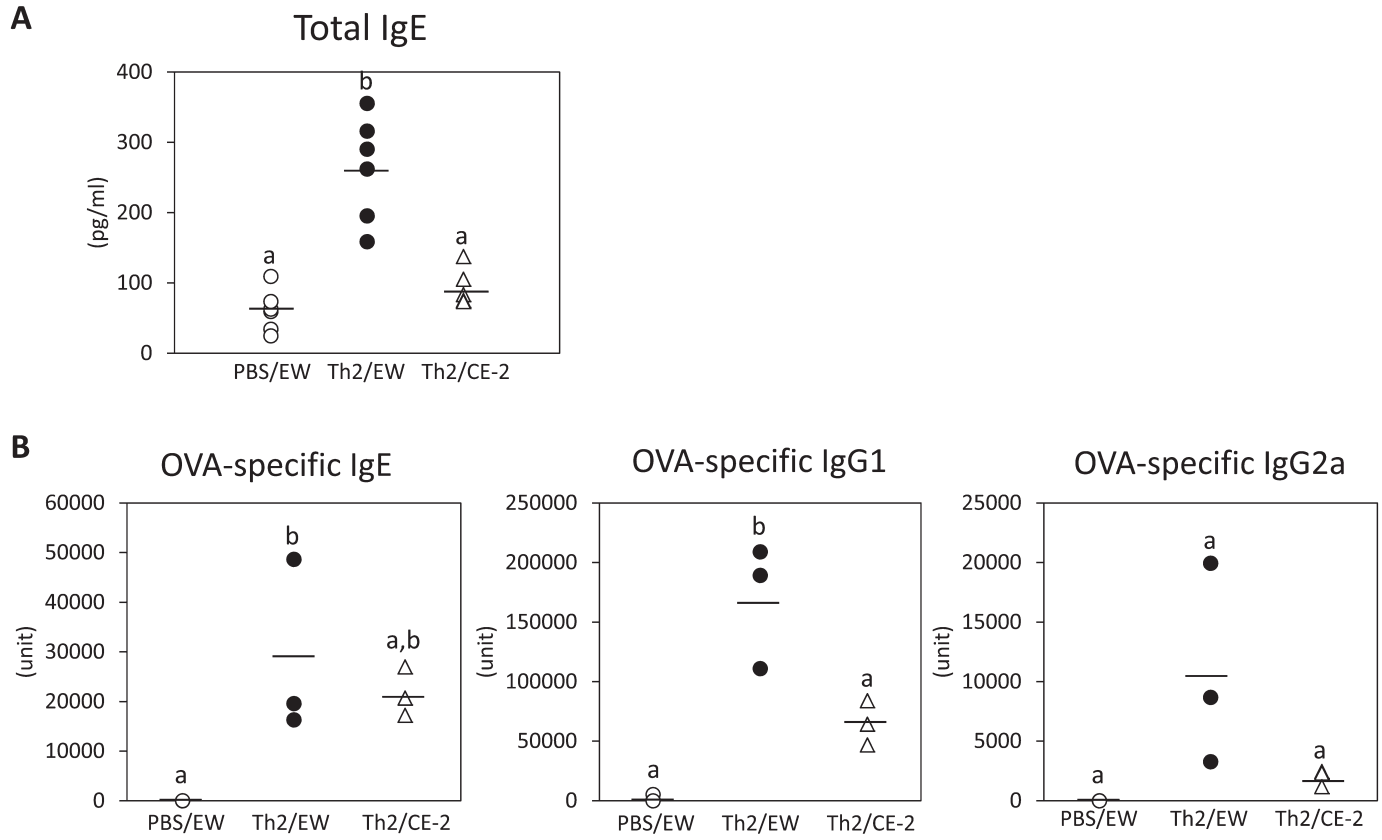

Fig. 3. Ig levels in the sera of Balb/c mice injected with Th2 cell culture or PBS, and fed the EW diet or CE-2 diet. Blood was collected from mice after feeding the EW diet or CE-2 diet for 14 days. Total IgE (A) and OVA-specific IgE, $\mathrm{IgG1}$ and $\operatorname{IgG2a}(\mathrm{B})$ in the sera were detected by ELISA. Experiments for OVA-specific Ig analysis were repeated 2 times with similar results. Plots and bars indicate antibody titers for each mouse and the means, respectively. Statistical analysis was performed by Tukey's HSD test analysis. Groups not sharing a common letterare significantly different $(\mathrm{p}<0.05)$.

Detailed study will be needed to clarify the reason for this, but significant stimulation via IL-4 receptor may enhance deletion of the $\mathrm{T}$ cells in the case of Rag2 $2^{-/}$ OVA23-3 mice.

In addition to OVA23-3 mice, DBA/2 mice were also reported to produce antigen-specific IgE following antigen feeding [14]. Antigen-specific IgE production in $\mathrm{DBA} / 2$ mice was elevated when they were fed a casein diet, not EW diet. The authors of that report mention that antigen-specific IgE production in Balb/c mice was not elevated by only casein or EW diet feeding. This suggests that the different immunogenic properties of each allergen and genetic background of individuals can play roles in IgE elevation. We showed here that OVA-specific IgE was elevated in Balb/c mice in response to an ingested antigen after injection of OVA-specific Th2 culture cells and feeding of an EW diet.

We have previously shown that feeding the EW diet to OVA 23-3 TCR transgenic mice induces intestinal inflammation accompanied by weight loss. However, we could not observe significant weight reduction in Th2/EW mice compared with Th2/CE-2 mice (data not shown). Furthermore, it was reported that $\mathrm{CD}^{+} \mathrm{T}$ cells isolated from food allergic inflammatory mice could mediate food allergic inflammation to naïve Balb/c mice [11] These suggest that, to evoke allergic symptoms in Balb/c mice, transfer of Th2 cells induced in vitro by rIL-4 and anti-IL-12 stimulation with splenic APCs is insufficient. Inflammatory DCs, which express OX-40L were reported to promote Th2 skewing [15]. Signaling from OX-40 on $\mathrm{T}$ cells may be necessary for differentiation into inflammatory Th2 cells, and this may be missing in the Th2 cell cultures we used.

In conclusion, our report showed that naïve Balb/c mice injected with an in vitro differentiated Th2 cell culture could respond to the oral administered antigen and evoke total and OVA-specific IgE. Further studies to establish effective protocols to induce Th2 cell cultures that can develop clinical symptoms by adoptive transfer may contribute to elucidation of some mechanisms of food allergy. For more general application to other allergens, it is desirable to induce antigen-specific Th2 cells from $\mathrm{CD}^{+} \mathrm{T}$ cells of wild-type mice in vitro and used them to elicit allergic inflammation. To develop this, the methodology indicated in the current study using Balb/c mouse will be useful not only to clarify the character of Th2 cells that mediate allergic inflammation but also to regulate the antigen-specific allergic response. 
Furthermore, this model may be useful in investigation of allergen-specific anti-allergic functions of food components.

\section{ACKNOWLEDGEMENTS}

We thank Y. Wakatsuki (Kyoto University) for originally providing the Rag2 ${ }^{--}$DO11.10 mice. This work was supported by Agri-health Translational Research Project from the Ministry of Agriculture, Forestry and Fisheries of Japan.

\section{REFERENCES}

1. Grundy J, Matthews S, Bateman B, Dean T, Arshad SH. 2002. Rising prevalence of allergy to peanut in children: data from 2 sequential cohorts. J Allergy Clin Immunol 110: 784-789. [Medline] [CrossRef]

2. Branum AM, Lukacs SL. 2009. Food allergy among children in the United States. Pediatrics 124: 15491555. [Medline] [CrossRef]

3. Sicherer SH, Sampson HA. 2010. Food allergy. J Allergy Clin Immunol 125: S116-S125. [Medline] [CrossRef]

4. Kumar S, Verma AK, Das M, Dwivedi PD. 2012. Molecular mechanisms of IgE mediated food allergy. Int Immunopharmacol 13: 432-439. [Medline] [CrossRef]

5. Takeda K, Gelfand EW. 2009. Mouse models of allergic diseases. Curr Opin Immunol 21: 660-665. [Medline] [CrossRef]

6. Aldemir H, Bars R, Herouet-Guicheney C. 2009. Murine models for evaluating the allergenicity of novel proteins and foods. Regul Toxicol Pharmacol 54: S52S57. [Medline] [CrossRef]

7. Corazza N, Kaufmann T. 2012. Novel insights into mechanisms of food allergy and allergic airway inflammation using experimental mouse models. Allergy 67: 1483-1490. [Medline]

8. Berin MC, Mayer L. 2009. Immunophysiology of experimental food allergy. Mucosal Immunol 2: 24-32.
[Medline] [CrossRef]

9. Chambers SJ, Bertelli E, Winterbone MS, Regoli M, Man AL, Nicoletti C. 2004. Adoptive transfer of dendritic cells from allergic mice induces specific immunoglobulin $\mathrm{E}$ antibody in naïve recipients in absence of antigen challenge without altering the $\mathrm{T}$ helper 1/T helper 2 balance. Immunology 112: 72-79. [Medline] [CrossRef]

10. Kweon MN, Yamamoto M, Kajiki M, Takahashi I, Kiyono H. 2000. Systemically derived large intestinal CD4(+) Th2 cells play a central role in STAT6mediated allergic diarrhea. J Clin Invest 106: 199-206. [Medline] [CrossRef]

11. Knight AK, Blázquez AB, Zhang S, Mayer L, Sampson HA, Berin MC. 2007. CD4 T cells activated in the mesenteric lymph node mediate gastrointestinal food allergy in mice. Am J Physiol Gastrointest Liver Physiol 293: G1234-G1243. [Medline] [CrossRef]

12. Nakajima-Adachi H, Ebihara A, Kikuchi A, Ishida T, Sasaki K, Hirano K, Watanabe H, Asai K, Takahashi Y, Kanamori Y, Shimojo N, Matsuda H, Kohno Y, Hachimura S, Kaminogawa S. 2006. Food antigen causes TH2-dependent enteropathy followed by tissue repair in T-cell receptor transgenic mice. J Allergy Clin Immunol 117: 1125-1132. [Medline] [CrossRef]

13. Nakajima-Adachi H, Koike E, Totsuka M, Hiraide E, Wakatsuki Y, Kiyono H, Hachimura S. 2012. Two distinct epitopes on the ovalbumin 323-339 peptide differentiating CD4(+)T cells into the Th2 or Th1 phenotype. Biosci Biotechnol Biochem 76: 1979-1981. [Medline] [CrossRef]

14. Ito $\mathrm{K}$, Inagaki-Ohara $\mathrm{K}$, Murosaki S, Nishimura H, Shimokata T, Torii S, Matsuda T, Yoshikai Y. 1997. Murine model of IgE production with a predominant Th2-response by feeding protein antigen without adjuvants. Eur J Immunol 27: 3427-3437. [Medline] [CrossRef]

15. Blázquez AB, Berin MC. 2008. Gastrointestinal dendritic cells promote Th2 skewing via OX40L. J Immunol 180: 4441-4450. [Medline] 